\title{
Archiving and Re-using of Qualitative Data as a Path to Development of Public Administration Research
}

Joanna Gajda

(iD) https://orcid.org/0000-0001-9107-0546

Pedagogical University of Krakow

Institute of Political Science

e-mail: joanna.gajda@up.krakow.pl

\section{Abstract}

In response to the assumptions of new public management models and public or good governance, practical aspects of research in the area of public administration and the development possibilities of qualitative research methods are presented in the article. Due to the fact that qualitative research has become increasingly popular in the above disciplines, data archiving and transparency is discussed (Moravcsik), (Yom et al.) and guidelines and principles are established (American Political Science Association). However, there is a lot of controversy among scholars (Monroe), and some examples are missing. This paper presents the challenge of 'openness' in the empirical activities (or empirical practice) of researchers. Its purpose is to present the archiving data potential from in-depth interviews on the example of a small set of qualitative data from research in the field of public administration. Firstly, the basic assumptions of new models of functioning of public administration and related consequences for researchers are described. In the second part, the challenges related to openness in contemporary public administration models are briefly mentioned. Next, the method of creating an archive from existing data, individual stages, documents, and data is outlined; it is based on the author's best practice on Qualidata (American Political Science Association; Van den Eynden et al.) and DA-RT principles. ${ }^{1}$ The summary includes examples of probable opportunities and challenges related to usage of data archiving for the research in public administration and political science development.

Keywords: Public Administration (PA), qualitative research, qualitative data, (IDI) In-depth interviewing, new public management (NPM), qualitative data archive 


\section{New models of public administration and the collection of qualitative data ${ }^{1}$}

Changes in public administration, from the model of Classical Public Administration (Weber classical theory of bureaucracy) through New Public Management to Public Cooperation (Good Public Governance) bring not only challenges to the administration staff but also researchers operating within this area. One of the principles of the new public management according to Kulesza and Sześciło is "institutional development management" (Kulesza and Sześciło). It imposes an obligation on the entire first sector of the economy and the people working to continually learn, improve and monitor effects of activities with a focus on economic efficiency, whose rules (management through results, performance-based budgets, citizen as a client) are related. However, the activities of the administration can not only be effective but are to serve public tasks; the employees are to be oriented towards the fulfilment of citizens' needs. Therefore, tension occurs between economic efficiency and social responsibility. For administration employees the model of comanagement is even more challenging, in which autonomous, competent, learning, committed individuals, i.e. people working in the administration have the opportunity or even the need to enter into partner relations with citizens (Mazur and Olejniczak). In addition, a clerk as an individual is to be focused on the quality of customer service. What is more, training documents for administrative employees published by the Chancellery of the Prime Minister ${ }^{2}$ contain an extensive list of required competences. Therefore, the expectations towards officials are high. In addition, administration staff is no longer to be regarded as a machine working to meet people's needs. The quality of customer service is examined by developing standards, indicators, procedures and methods.

For researchers active in this area processes, results, decisions, policies, activities, etc., are interesting specifically the various aspects of performing tasks and mechanical actions. However, if new models of administration are to be examined, the process cannot be limited to the inquiry of the officials about the stages of investment implementation. It is worth mentioning that how respondents are perceived influences what is studied and how it is inferred. There is a risk that when officials are involved in the research, the subjectivity is not reflected as models of new public management (NPM) and co-management would have it. Respondents are treated rather as an element of the bureaucratic machine. Co-management is

1 Qualidata is one of the examples of system for collecting data in qualitative research (Main Web). More about archives: Gajda; Filipkowski; Parry and Mauthner; Harrison; DA-RT - Data Access and Research Transparency.

2 Among others The Chancellery of the Polish Prime Minister. Final report. Guidelines for implementing customer satisfaction management standards in government administration offices, Warsaw 2012, https://dsc.kprm.gov.pl/sites/default/files/pliki/zal._3.pdf [10.08.2018]. 
the ability of the state to serve its citizens and to be open to them: it is the quality of services and communication that is taken into account. Therefore, attention can be focused on the study of service providers - their thoughts and opinions (of officials and managers) and the challenges they face while fulfilling their duties. Consequently, not only the quantitative aspect of administration activities can be studied by asking: how many?, how much?, etc. but also the qualitative aspect can be researched by answering the questions: why? how?, etc.

While reviewing the literature on the subject, it can be pointed out that in administration as an area both quantitative and qualitative research and mixed methods can be implemented. On the one hand, in the period 2001-2010, the qualitative approach prevailed: "Results show that the qualitative methods are still predominant compared to quantitative methods (56\% versus $44 \%$ ), the field is becoming increasingly quantitative" (Groeneveld et al.)605 articles published between 2001-2010 in four leading journals: Journal of Public Administration Research and Theory (JPART). However, another author indicates that in the period 20102014 the quantitative approach was dominant: "Qualitative work represents a small percentage of the journal articles published in the field" (Ospina et al.). As both sources indicate, the approach that is the least frequently mentioned, involves combining quantitative and qualitative analyses.

Another consequence of the new models of administration is the future of data collected by public institutions and researchers. Co-management requires being opened, defined “as citizens' access to knowledge about administration activities, participation, accountability, effectiveness, coherence understood as co-ordination and integrity of implemented programs, strategies and policies" (Anders-Morawska and Rudolf). The above assumption has consequences for researchers in the need for archiving and sharing data. Public access to quantitative data generated by the administration becomes a reality. The trend for open data in connection with the cooperation of administration with researchers is being developed in some states of the USA (Graham et al.), through joint projects and analysis. Openness applies both to administration and research activities. ${ }^{3}$ The administration obtains important information for its activities and outsources research to scientific institutions. As part of this partnership, the respondents agree, on the terms of cooperation, to fulfil longitudinal studies - repeated in the long term - and analyze cohorts in particular groups. A specific attitude towards sharing quantitative data can also be noticed in Poland. Access to data is possible not only on the GUS platform, ${ }^{4}$ but is also offered by the Open data site https://dane.gov.pl/, which allows citizens access

3 Data Access \& Research Transparency, Home Page, https://www.dartstatement.org/, [12.07.2017]. The guidelines have provoked a discussion in social science and will be the subject of another publication.

4 Główny Urząd Statystyczny - General Statistical Office, Databases, http://stat.gov.pl/banki-ibazy-danych/ [5.05.2018]. 
the required data. ${ }^{5}$ Thus, there is an awareness of the value of the quantitative data and the need to share them. As the above-mentioned American example suggests, this practice is most effective when both parties use and clearly establish rules for sharing and processing data. In data access, there is always a strong tension between openness and privacy (Graham et al.).

Archiving and sharing data is the basis for cooperation between disciplines. The qualitative data archiving, which will be discussed more in the further part of the article, could be particularly interesting (Moravcsik; Nosal). For political scientists who might be interested in political decisions, leaders, decision processes, the exercise of power, authority and conflict, administration employees may seem more accessible and more interesting than politicians. The employees of self-government and administration are closer to the citizen, so they are really connected with decision-making processes, experience all stages of decision implementation, have the opportunity to observe changes, are involved in conflicts, see how authorities change, are not separated from public opinion, and their work involves meeting clients-citizens. Officials seem, on the one hand, to be people with individual opinions, but on the other hand, they are public employees representing the selfgovernment, and therefore are more like institutional entities. Their own views, opinions, motivations are important but should not determine their actions. Therefore, the question to be asked is what assumptions are - are the processes investigated, or people's thoughts about the process's trajectory, or maybe in the course of research the views and motivations of people working in there are recognized. As mentioned above, each question in interview scenario and then answers coding are assumptions that point out what the researcher actually analyses, not as it is declared. If the questions are about the number of projects, their course - dates and means, the number of participants, advantages and disadvantages then we get to know the perspective of perfect bureaucracy. The research does not present the perspectives of participants creating services and partnerships in the New Public Management and Co-management Model.

As it is assumed by the model of co-ordination, in principle, the society has the right to know and has the right to information. Consequently, it can be assumed that officials should take part in research - researchers have the right to obtain full information from them. However, IDI (in-depth interviews) are to reach not only official records, as the opinions of the respondents are also of interest. A good IDI requires the involvement of respondents and their openness; people being forced to participate in the interview are not a good source of information. This is also affected by the fact that the researcher who collects data in the administration is in some way biased because as a scientist he/she approaches the organization with

5 At the time of this article submission, on 22.11.2018, the following material was published by the Ministry of Digitization: Opening Data. Handbook of Good Practices. https://dane.gov.pl/media/ ckeditor/2018/11/22/otwieranie-danych-podrecznik-dobrych-praktyk.pdf [22.11.2018]. 
the preconceived idea about its operations. Thus, it might be difficult to establish the necessary partnership. Therefore it is a very important aspect of the research implementation in every organization and especially in administration. This is a problem described by Monika Kostera who notes that the respondent is a researcher's partner and his/her actions should not be evaluated by the researcher. Thus, in the interpretative trend in the organization's research: "first of all, we do not give piece of advice to practitioners. (...) Practitioners are essential for us to learn from them, how to practically organise and manage. We [the researchers] are necessary for them that they are able to get away from their everyday reality in search of something new or maybe something unimaginable. They can manage themselves" (Kostera).

Accordingly, what a qualitative researcher can offer to respondents is a different perspective on the given issues, but only through asking questions, hence using more of the coaching approach. Researcher - if non-involving research is conducted (opposite to action research which predicts a direct impact on the respondents) - has no right to suggest solutions or influence the examined person. The fact is that the interview between the researcher-researched person affects the reality of both actors. Such a meeting may give the examinee a different point of view and inspiration, disturb him or her, make them worry or interested. In qualitative interviews, interesting questions can be asked by respondents who find out that research is carried out in other cities and ask how others are doing/ having/thinking. The organisations under study are interested in how the researcher assesses their actions or thoughts. The comments such as: "I have never thought about it," "I have to think about it," "interesting question," "I have never had time to consider it," "It's good that you ask about it" appear. In a well-prepared interview, respondents may feel appreciated as specialists, people in the position, etc. Thus, the ordinary human aspect of the researcher-researched entity relation can be still visible. A qualitative interview as a method of choice is also supported by the fact that: "In-depth interviews with government officials are a critical research method of government" (Jiwani and Krawchenko) and particularly the informal internal dynamics that influence policy, require a depth of understanding that is often best investigated through such interview methods. At the federal level in Canada we see many trends that point to the increasing centralization and control of government information. There has been political interference in Access to Information Requests; the outcomes of scientific research have been suppressed; and media access to politicians has become highly constrained. This led us to ask whether tightening controls on information have also affected access to research interviews with government officials. This paper explores this issue by interviewing both academics and public servants in the Canadian federal government. We ask is there evidence of a tightening grip on access to governmental research interviews and, if so, is this affecting how and 
what we research? (Jiwani and Krawchenko). Such an approach can be treated as adequate for a co-ordinated model implementation, and well-implemented qualitative research can bring valuable effects to both sides - escalating relations as partners. Despite the benefits of qualitative research, the public administration as a study area is a big challenge, primarily due to the fact that these studies absorb a lot of time, energy and money. For researchers, they are an extraordinary intellectual-financial-organizational-logistic challenge. As mentioned earlier, they require much larger involvement of the administration staff, who have to spend a lot of time on them rather than on clicking on the questionnaire. The question appears whether participation in the study should not be treated as a job assignment that directly benefits the community. It might be assumed that the time devoted to research is for the development of science, but not exclusively, as the community will benefit from the results of research, so it is worth for the researcher to foresee some benefit for society.

The next problem is limited access to the administration employees. The technical challenge is to get approval for research, to arrange, and carry out studies; there is no homogenous procedure to obtain research permissions in Poland. Usually, a request to conduct a study is directed to the person managing the office/unit. Recruitment is carried out among managers, probably assuming that they have the widest knowledge in the studied area. It happens that a managing person assigns an employee to research, then the employee receives an official order to participate in the meeting. As a contrast, the researchers describe the situation in Canada before 2014, where officials were unwilling to give interviews. The authors describe that the official procedure of the invitation for research was not effective and the officials did not want to talk in the office (Jiwani and Krawchenko). The strict procedure that makes participation in the research obligatory can be harmful for the study in question. From the perspective of the qualitative research implementation, the law and civil servants guidelines are less significant. What matters more is the attitude and sense of mutual benefit from cooperation between researchers and the institution. As Canadian example points out, although access to data will be facilitated by the introduced law - without "openness" it is increasingly difficult to carry out qualitative research in administration (Jiwani and Krawchenko). For example, in Canada, "federal government is undermining access to public servants" (Jiwani and Krawchenko). In the Polish environment it happens that the person managing the office does not agree to participate in the study, and people working in the office do not have the opportunity to participate in research if their superior does not agree. In comparison, in Canada it was observed that in general officials did not respond to a formal invitation to participate in the research, they only agreed to research if it was possible to talk off the record.

The next common problem revolves around the inadequate knowledge of researchers about the real attitude of all the officials towards the studied problem. 
In qualitative research it is rather the one who speaks that has the power and authority or the sense of it. The superiors speak more willingly and often more confidently than regular employees. Lower-level employees have a lot of doubts about what to say and whether what they are saying would be consistent with their supervisor's opinion. The problems with access to administration employees described by researchers (Jiwani and Krawchenko) is also noticeable in Polish conditions. As part of their research in public administration in Canada, they point out that only access to superiors (senior public servants) is possible. Due to their work specificity and considerable responsibility, they are hard-to-reach people and have no information about everyday routine activities. Lower-level employees, those who are involved in the implementation of decisions, contact with the citizens, conflicts and negotiations of specific elements of the activity, want to be loyal to their superiors and if they are appointed to participate, the conversation depends a lot on their relations with the supervisors. Sometimes, they are less willing to express their own opinions, indicate their lack of right to speak, refer to the knowledge of other people. Managers are resistant to talk about the programs' implementation and more about politics and strategy ("senior public servants will differ from those with less elderly ones," Jiwani and Krawchenko) and it happens that they are more afraid of assessments from the researcher, seeking the confirmation from their assemblies. They are also dependent on the people who have appointed them for the position and want to meet their expectations. According to the researchers, the respondent who participates in the study influences the subject of the research and conclusions that can be formulated (Jiwani and Krawchenko). The best informants seem to be those who despite the efforts undertaken at the stage of the study design the researcher might not get access to. One solution to these dilemmas might be talk to officials who retire because they are not burdened with dependencies, are more anonymous and may look from distanced (lukewarm) point of view at the matters falling within the scope of our interest.

As indicated by researchers dealing with qualitative research in the PA area, the most significant issue, though, is that only a small number of published qualitative studies in PA journals can be considered a breakthrough (Ospina et al.). In the area of public administration, as in other areas, a discussion is going on about the quality of qualitative research, allegedly not bringing anything new to science and reproducing old truths. A suggestion for researchers is development of cooperation in the environment, in other words: "A deeper understanding across the epistemological divide will build methodological pluralism and enhance readers' ability to evaluate the work of colleagues. A possible strategy is to foster conversational spaces-in conferences" (Ospina et al.). The second proposal requires compliance with the standards or else "Scholars should care about methodological reporting standards, as this can enhance research credibility for policy makers" 
(Ospina et al.). That would be possible only if a list of such standards was created or the results of work were shared and were raised for substantive discussion.

The above-mentioned opportunities and challenges brought by the application of interviews with administration employees resulted in the idea of archiving data from public sector research to enable good quality and in-depth analysis. The proposal of archiving and sharing qualitative data presented below supplements the proposed solution of the ongoing cooperation between researchers. The presented example of an archive building offers an opportunity for the researchers in the field of PA to improve the quality of their analyses while saving time of the potential candidates for interviewed officials. It also proposes a formalised manner of collaboration within the groups of researchers. Archiving interviews could give an opportunity for: an increase of quality analysis by allowing access to data for young researchers and $\mathrm{PhD}$ students, facilitating comparative study design by offering access to data, the establishment of good practices of research and expansion of knowledge within particular areas of study rather than duplication of research topics and approaches. The database presented below is the result of several years of work on identifying subjects of secondary analysis and archiving data and sharing the acquired knowledge at conferences and seminars. The author postulates the creation of quality databases and the application of retrieved data in political analysis related to changes in the public sector. The following example is based on the author's several years of interest in archiving qualitative data, and analysis of state of art on this field that resulted in a doctoral dissertation based on Qualidata and DA-RT procedures. Since 2012 in Poland, there has been a strong inclination towards the creation of qualitative data archives (Nosal), which is also present in the international debate in the field of political science. There is only a lack of substantive discussion regarding archiving practice. The record of procedures in this area comprises universities (e.g. King's College London), companies (e.g. EDF-Verbatim), research funding institutions (e.g. The Economic and Social Research Council), organisations (e.g. Institute for History and Biography) and associations (e.g. APSA). In Poland, internal archive procedures are unfortunately not available on websites and existing archives, due to the costs of preparation of the collections. However, high-quality research requires the development of strategies for preparing materials in response to the challenges of accessibility and transparency. The example below indicates the challenges that arise when archiving is carried out after the project has been completed. The procedure of creation of the archive is described in the section below. 


\section{Database of preliminary information}

The database contains data collected in 2012 as a part of the project titled Marketing as Operational Development of Governance Concept in Public Management. The project was completed within the Faculty of International and Political Studies at the University of Lodz. The official name of the archive is The Concept of Governance in City Management. Authors of the studies: Justyna Anders-Morawska, Wawrzyniec Rudolf 2012. The author of the archive is the author of this paper. Interviews were carried out in eight Polish cities with metropolitan potential or serving as strong regional centres. Primary researchers chose 18 interviews to create the database. Due to financial limitations, 15 interviews were transcribed.

The qualitative empirical process in the original project had two stages (AndersMorawska and Rudolf). The structure of the interview scenario with respondents representing the city was mirrored in the scenario adressing the representatives of institutional stakeholders. This stage of research involved representatives of legal entities that were important for the local structures of the city governance. The research outcome is presented below:

Stage I (city) - the following respondents took part:

- City president or city vice president (depending on availability).

- Directors or deputy directors of specific departments in the city council - by list.

- City councilors (chairman or vice-chairman of selected committees of the city council - by list).

Stage II (institutional stakeholders) - the following respondents took part:

- Directors or deputy directors at the Marshal Office (by list) - interviews marked by letter $\mathrm{M}$ and first letter of the name of the city.

- Directors or deputy directors of institutional stakeholders of the city (Regional Tourist Organization, University College, Regional Development Agency) - interviews marked by letter I and first letter of the name of the city.

The project required initial contact with the managers of public institutions; appointing coordinators and local interviewees; and arranging meetings and reinvitations to the studies. Then the local coordinators and interviewees received the scenarios. The research was carried out in the following way: interviews were handled by the project coordinator, the deputy coordinator and the persons recruited for the interviews. The interview proceeded in accordance with the semi-structured scenario adjusted to the specificity of the office positions of the respondents (performed functions, tasks carried out). At the same time, the tool was a template for creating a grid by an interviewer. The tools contained open and closed questions. A detailed methodology of the project, and respective research tools are described in a monograph, that was a result of the project: Orientacja rynkowa we wspótrządzeniu miastem (Anders-Morawska and Rudolf). 


\section{Basic assumptions of data archiving and re-analysis}

The collected data concerned not only the subject of research, so the project coordinators were asked to preserve the research material for educational and scientific purposes. Archiving of qualitative data is related to the assumption that the collected/generated data is a photographic-like reflection of reality at a given moment in time - it has never happened before or will not ever since. With respect to respondents and examiners, it can be verified whether data can be the basis for answering new research questions and supporting scientific projects (Gajda). Data backup and longitudinal tests are also possible thanks to data archiving.

The first stage of the analysis reassesses how much data can be valuable for further analysis; it also requires a re-evaluation of the materials gathered within the project, i.e. those that the original researcher wants to share, and answering several questions that will verify the data potential. At this stage, the key (from the ethical perspective) was to get the permission of: a) the primary researchers to study the data set and make them available. In the end, the original researcher decides about the possibility of using the data, who, how and in what topic can use it, b) the researched units about the usage of data for scientific purposes. In the ideal pre-interview research procedure, the written consent of the respondents to the archiving and re-use of data (British experience) is obtained. In a situation when the methodology is new in Polish science and there is no practice of implementing such agreements, ${ }^{6}$ it is necessary to make a decision based on the assumptions of primary researchers. The qualitative data archives created in Poland are a place where researchers can deposit their collected materials ${ }^{7}$ but there is still no practice of thinking about archiving while planning research. ${ }^{8}$

Due to the fact, that interviews were made with employees of the institution that agreed to perform the research and data analysis without indicating that the data should be destroyed after the analysis, they remain at the disposal of the researcher acting in good faith (the basis for decision-making might be a comment and a reference to the personal data protection law). The use of materials for scientific and didactic purposes allows processing of personal data for a different purpose than they have been collected for. It should be noted that the emerging threats in the area of the GDPR did not change anything in the area of scientific data processing by primary researchers.

The relation between the researcher and researched entity should be verified with care, based on documents (tools and notes) and interviews, information the researcher obtained, and the terms of study that the parties agreed to. Data

6 More: https://www.ukdataservice.ac.uk/use-data/guides/methods-software/qualitative-reuse [19.10.2018].

7 E.g. in: Quality Data Archive, Daily Life Research Archive, etc.

8 E.g. in: The Social Science Research Council. 
anonymisation is required after preparing the data transcription. However, it is not necessary if we do not collect sensitive data. Finally, anonymisation of the data in the presented set was not necessary, because the data is still at the disposal of the original researchers. During the re-use of data, attention should be paid to the respondents' requests for data anonymisation indicated in the notes, which in practice will mean that in using the data the researcher will undertake the necessary means to protect the identities of the respondents. The collected database is a full record of interviews. The course and the effect of base creation are described in detail in the next section.

\section{Preparation for database creation}

In order to be able to archive the data, certain arrangements had to be made with primary researchers. That is why a conversation was held with the coordinators, and its summary was included in the database. While deciding to archive data of other researchers, it is worth to write down the arrangements that have been made and place them in the database as a document. The summary should contain answers, among others, for the following questions:

1. Q: What is the rationale of creating a base?

A: We create a qualitative database for didactic use and for own scientific work (each page informs about the use of data).

2. Q: How many copies of the database should be created?

A: 2 copies are created, each of the files is described in the document (which can be found in the file). In addition, the database contains a spreadsheet, in which there is a summary of interviews (keywords, main themes, interview situation, etc.).

3. Q: What kind of data are placed in the database?

A: The data concern the local governments activities, the cooperation of local governments with institutional stakeholders in several areas.

4. Q: What are the sensitive data in interviews and how to protect them?

A: There are several potential ethical issues: the people who spoke were very honest (personal judgments). The confidentiality of data should be preserved, information about researchers and subjects are classified as protected.

5. Q: What keywords describe the base?

A: The database can be described using words such as: inter-organisational relations, interactions, cooperation, local government, city management, co-management and governance processes.

6. Q: What information about the project should be provided when using the database? 
A: In the publication, the following bibliographic note should be inserted: Governance Concepts in City Management. Authors of the Study: Justyna AndersMorawska, Ph.D. Wawrzyniec Rudolf, Ph.D., 2012.

This set of information was stored in the folder CC. Archive arrangements.

In the case if at the next stage the original researchers decided to share the data with other researchers, it would be necessary to write down the following questions: Who and on what principles should the data be made available to? What data can be left in the transcripts, what should be anonymised? Based on the above-mentioned agreement from July 2016, the tools for the re-analysis of the data were the obtained recordings and notes. Up to 15 interviews were available for transcription. Recordings for transcription were chosen by primary researchers, due to the limited amount of resources, three interviews were not transcribed. When preparing a database, attention should always be paid to the file format, e.g. the Maxqda program does not read audio files in .amr format. Therefore, before building a database, it is worth considering the tools used in the analysis and checking what kind of systemic constraints may appear.

\section{Data sorting}

Finally, instructions, information for researchers, auxiliary data, procedures, and data were structured and stored in 4 folders:

1. Data - data set arranged in accordance with the arrangements with the primary researchers.

2. Arrangements - a folder with a file with arrangements for the archive, which is a contract between research coordinators and the researcher who is the author of the archive. This folder should also contain information for researchers who want to work with the archive at the time of its availability.

3. Using the database - a folder containing documents regarding the use of data. Basic information about re-analysis, information about the project from primary researchers, description of the archive, data sharing card.

4. Maxqda data set $-\mathrm{a}$ folder with files ordered in the program for qualitative data analysis ordered by coordinators.

5. Instructions for using the database - a file containing a short outline how to deal with the database.

The picture below shows the organisation of the archive: 


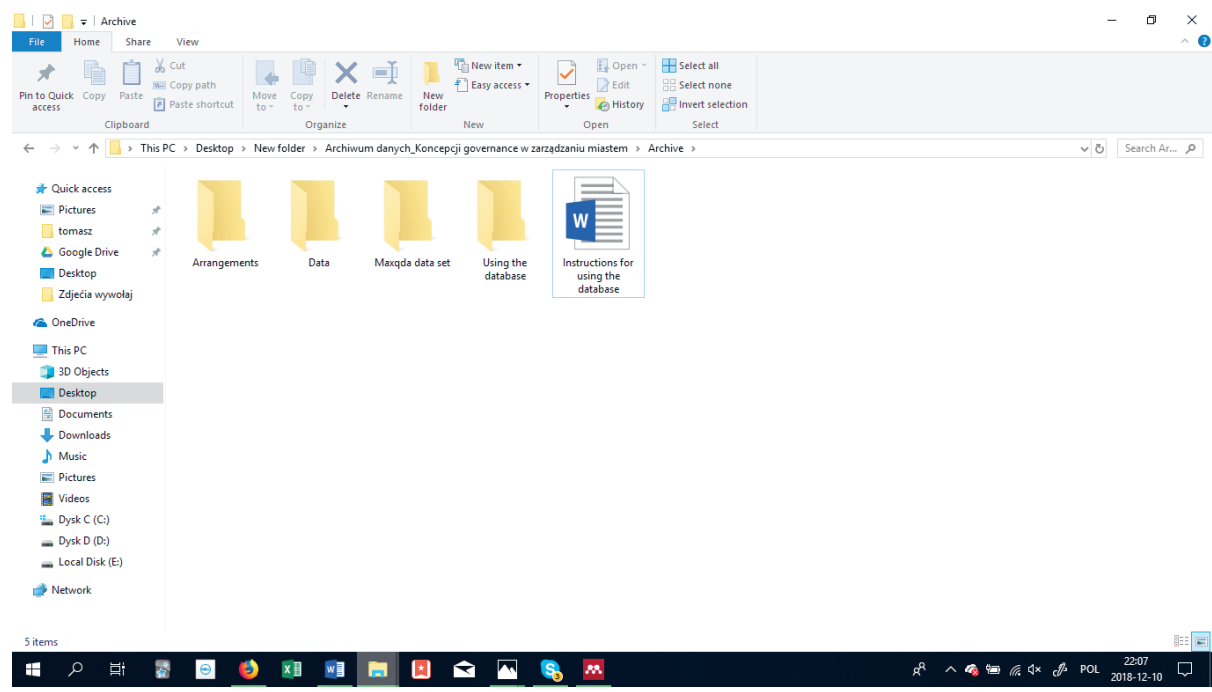

Figure 1. Archive folders

By placing the obtained files in one set and systematic review of the data, it became possible to identify deficiencies, organise the interviews and divide them into groups of documents assigned to cities. Some file names have been changed for data sorting purposes. Changing names is quite a challenge, as there are no guidelines. Based on the author's earlier projects and experience short labels for individual file types were selected. The following abbreviations have been used:

Not - an interview notes - grid prepared in 2012 by an interviewer conducting an interview, or by a primary researchers. Based on the grid, the primary analysis was made and the publication was created. Trans - transcript of the interview prepared in 2016, funded by the research for young scientists of the Pedagogical University as part of project: The valuable data - exploration of the potential of qualitative data, project supervisor: Joanna Gajda. Nagr - interview recording prepared by the interviewer; if the recording is divided into parts, they are numbered from the first $(1)$ to the last $(2,3,4)$. The titles of the recordings and transcripts of interviews were to help in their ordering; the following shortcuts were used in consultation with primary researchers: $\mathbf{P}$ and the letter of the city - self-government authorities, employees of the City self-government. $\mathbf{M}$ and the letter of the city - institutional stakeholders - Directors or deputy directors at the Marshal Office.

I and the letter of the city - institutional stakeholders, Directors or deputy directors of the institutional stakeholders of the city (Regional Tourist Organization, University, Regional Development Agency.) As a result, the following set of files was obtained: 


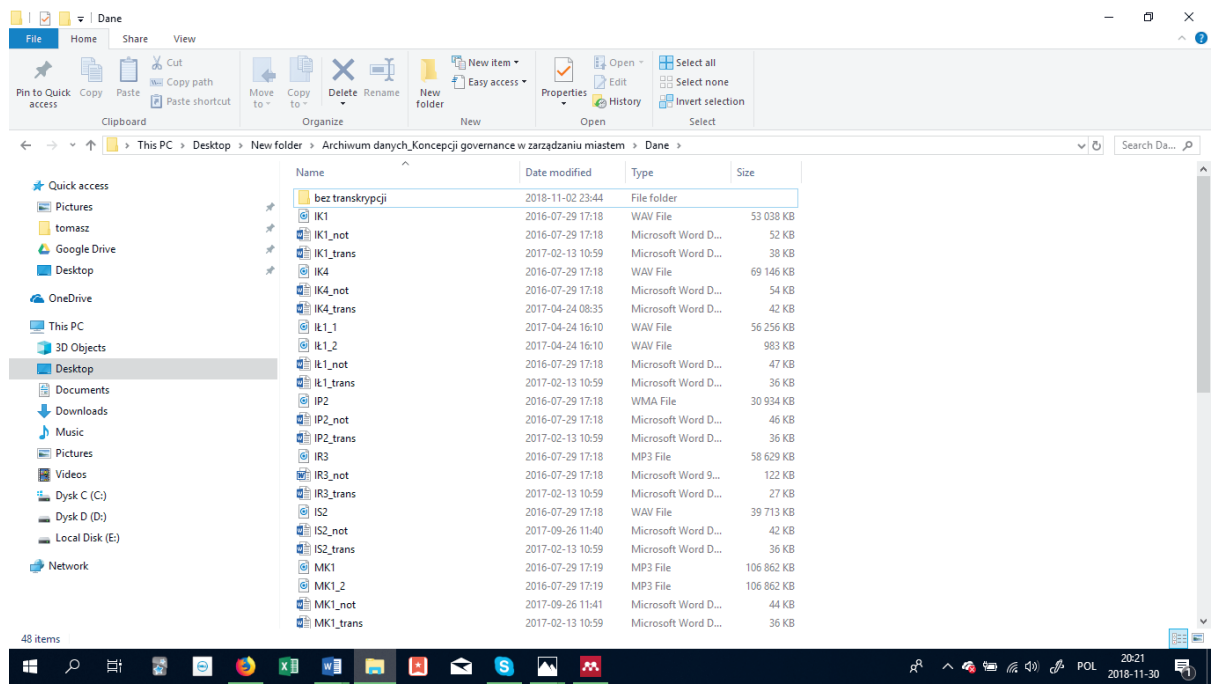

Figure 2. Data List

The main beneficiaries of the archive are the research coordinators, so it must be clear and helpful to them; it cannot impose solutions that they do not accept. For the preparation of the archive documentation, the instruction was used that had originally been the basis for the creation of the British database QUALIDATA:

"Good data documentation includes information on:

- the context of data collection: project history, aim, objectives and hypotheses,

- data collection methods: sampling, data collection process, instruments used, hardware and software used, scale and resolution, temporal and geographic coverage and secondary data sources used,

- dataset structure of data files, study cases, relationships between files,

- data validation, checking, proofing, cleaning and quality assurance procedures carried out,

- changes made to data over time since their original creation and identification of different versions of data files,

- information on access and use conditions or data confidentiality"(Van den Eynden et al. 9).

The set also provides data in the Maxqda program prepared for analysis. The database was forwarded to primary researchers on Oct 5-6, 2017. However, the most important is the file that is the data usage instruction. 


\section{The summary}

To sum up, the archiving procedure proceeded as follows:

- primary researchers decided to select the interviews for archiving;

- the researchers provided interview recordings for transcription and interview notes;

- in the initial stage, the submitted recordings were sorted out, the names of the interviews were verified, the notes for the interviews were adjusted, duplicates of the documents were identified in the database;

- the data were ordered on the basis of practices derived from Qualidata assumptions and DA-RT procedures;

- 15 interviews were selected for transcription, assuming the diversity of the methods of conducting the interview and its processes;

- 15 out of 18 interviews were transcribed;

- An outline has been developed to make the data available in accordance with the system operating at the Quality Data Archive (ADJ), and the KARTA Center Foundation.

The above procedure assumes access to data on-site (Łódź, Kraków) by the courtesy of the original authors who may become acquainted with the purpose of the research and make a decision to share the data or not. To enable the use of data, it was proposed to use the DATA USAGE OUTLINE CARD WER 1.1. If primary researchers want to transfer data for re-analysis to other researchers, they will be able to use the above document. The work and consultations of the data sharing card are still in progress for other projects.

The existing database is an example of the ability to share data, potential experiences exchange of knowledge and learning from past research. It does not contain only perfect interviews. Nevertheless, it allows analysing the work of interviewers and the statements of the officials. It was created based on the assumption that qualitative data are valuable material that should be respected. To make better usage of the time of researchers and officials involved in the studies on PA, it is possible to encourage primary researchers to cooperate by creating small databases of interviews enabling the implementation of analyses for the community. Their creation may be a fundamental issue for the postulated development of qualitative research in PA. At the same time, it allows the prospective researchers to construct the vocabulary of an interview in the language of the respondents, to search for good practices in the implementation of interviews, and to identify errors that can be avoided in subsequent surveys.

This database sample is intended to enable researchers to reuse data, create material for teaching and material for comparison and analysis. It is worth pointing out that: "Qualitative research is about being closer to the subjects: the 'direct encounter" (Blackman). Therefore, such databases are potentially valuable for all those who are interested in the subject of public administration and local government. 
"This makes it even more important to conduct longitudinal research, including impacts on methods of inquiry and policy sectors. This was a study of the public policy academics" (Jiwani and Krawchenko). In the end, without data archiving, longitudinal studies are not possible. Therefore, the author postulates that during the planning of qualitative research in the area of public administration, archiving data obtained through interviews is considered. Such activities may allow the most effective use of resources (time, money, the potential of administration and research workers) and create an area for exchange of experience. Having even a small set of data archived, we become partners for a discussion with other researchers. We can improve our skills and our understanding of the subject, use data more effectively, intensify analysis, run longitudinal studies, compare results, and ask new questions. This allows the improvement of the quality of qualitative research and finding new areas, e.g. considering public officials as partners whose opinions and motivations are interesting in an epistemic sense. This article could be an example of the practical answer to the issue of the expectation of transparency and replication in social science. It presents a procedure that can be implemented by every researcher in Poland and that is also in accordance with international standards. The author shares this experience of creating a database in hope to open a discussion in this area.

\section{Works Cited}

American Political Science Association. A Guide to Professional Ethics in Political Science. 2012, http://www.apsanet.org/portals/54/Files/Publications/ APSAEthicsGuide2012.pdf. Accessed 20 Jun 2018.

American Political Science Association. DA-RT - Data Access and Research Transparency. https://www.dartstatement.org/. Accessed 6 Aug 2018.

Anders-Morawska, J., and R. Wawrzyniec. Orientacja rynkowa we współrządzeniu miastem. Łódź: Wydawnictwo Uniwersytetu Łódzkiego, 2015.

DA-RT - Data Access and Research Transparency. American Political Science Association About, https://www.dartstatement.org/. Accessed 6 Aug 2018.

Data Access and Research Transparency (DA-RT): A Joint Statement by Political Science Journal Editors. "Italian Political Science Review/Rivista Italiana Di Scienza.” Politica 45.2. (2015): 103-104. http://dx.doi.org/10.1017/ipo.2015.12

Filipkowski, P. "Po co archiwizować dane jakościowe i jak robią to inni." ASK. Społeczeństwo. Badania. Metody 14 (2005): 31-52.

Gajda, J. Application of Qualitative Methods in Political Science Research, unpublished doctoral thesis, defended 3 Mar 2015, Faculty of International and Political Studies of the Jagiellonian University.

Graham, F. S., et al. "Navigating the Transparency-Privacy Paradox in Public Sector Data Sharing." American Review of Public Administration 46.5 (2016): 569-591. 
Groeneveld, S., et al. "Quantitative Methods in Public Administration: Their Use and Development through Time." International Public Management Journal 18.1 (2015): 61-86.

Harrison, H. M. "Inside the SED Archives: A Researcher's Diary." Cold War International History Project Bulletin 2.20 (1992): 28-32.

Jiwani, F. N., and T. Krawchenko. "Public Policy, Access to Government, and Qualitative Research Practices: Conducting Research within a Culture of Information Control." Canadian Public Policy 40.1 (2014): 57-66.

Kostera, M. Antropologia organizacji. Warszawa: Polskie Wydawnictwo Naukowe 2013.

KPRM, Guidelines for Implementing Customer Satisfaction Management Standards in Government Administration Offices. Warsaw 2012, https://sc.kprm.gov.pl/sites/ default/files/pliki/zal._3.pdf. Accessed 10 Aug 2018.

Kulesza, M., and D. Sześciło, Polityka administracyjna i zarządzanie publiczne, Warszawa: Wolters Kluwer, 2013.

Main Web, https://discover.ukdataservice.ac.uk/QualiBank. Accessed 10 Jul 2019.

Mazur, S., and K. Olejniczak. "Organizacje uczące się. Model dla administracji publicznej.” Organizacje uczace się. Model dla administracji publicznej. Ed. K. Olejniczak, Warszawa: Wydawnictwo Naukowe Scholar, 2012, pp. 23-60.

Monroe, K. R. “The Rush to Transparency: DA-RT and the Potential Dangers for Qualitative Research.” Perspectives on Politics 16.1 (2018): 141-148.

Moravcsik, A. “Transparency in Qualitative and Multi-Method Research.” Institute for Scientific Information 47.1 (2014): 6.

Nosal, P. “(Selektywne) Zwierciadło bazy danych o dwóch wymiarach baz danych w kontekście archiwum badań nad życiem codziennym." Kultura i Społeczeństwo 3 (2015): 157-183.

Ospina, S. M., et al. "Assessing Qualitative Studies in Public Administration Research." Public Administration Review 78.4. (2018): 593-605.

Parry, O., and N. S. Mauthner. "Whose Data Are They Anyway? Practical, Legal and Ethical Issues in Archiving Qualitative Research Data.” Sociology 38.1 (2004): 139-152.

The Social Science Research Council, Qualitative Data Repository, Managing Qualitative Social Science Data. An Interactive Online Course, https://managingqualitative-data.org/. Accessed 10 Sep 2019.

Van den Eynden, V., et al. Managing and Sharing Data. Best Practice for Researchers, UK Data Archive, University of Essex. http://www.data-archive.ac.uk/media/2894/ managingsharing.pdf. Accessed 10 Jul 2018.

Yom, S., et al. "Making DA-RT a Reality.” PS - Political Science and Politics 47.1 (2014): 72-77. http://dx.doi.org/10.1057/eps.2015.83.

Ziętal, K. "Udostępnianie materiałów archiwalnych." Archiwistyka Społeczna. Podręcznik. Ed. K. Ziętal, Warszawa: Ośrodek KARTA, 2012, p. 133. 
Joanna Gajda, PhD - political scientist and sociologist. She lectures at the Pedagogical University in Krakow and works as a certified social competence trainer according to the HRDBP standard. She holds an office of the Assignee of the Director of the Institute of Political Science for student internships. She specialises in research planning and implementation, analysis of qualitative data and evaluation. Her fields of interest are qualitative research, archiving qualitative data and its re-analysis. 